Original article

\title{
Willingness to donate blood and associated factors among patient caregivers at the University of Gondar Comprehensive Specialized Hospital, northwest Ethiopia
}

\author{
Azmeraw Ambachew Kebede ${ }^{\mathrm{a}, *}$, Yirga Bitew ${ }^{\mathrm{b}}$, Tiruye Birku ${ }^{\mathrm{b}}$, Zemenay Member ${ }^{\mathrm{b}}$, \\ Wubijig Achenef $^{\mathrm{b}}$, Nebiyu Solomon Tibebu ${ }^{\mathrm{a}}$, Tazeb Alemu Anteneh ${ }^{\mathrm{a}}$ \\ ${ }^{a}$ Department of Clinical Midwifery, School of Midwifery, College of Medicine and Health Sciences, University of Gondar, Gondar, Ethiopia \\ ${ }^{\mathrm{b}}$ North Gondar Zone, Amhara Regional Health Bureau, Amhara, Ethiopia
}

\section{A R T I C L E I N F O}

\section{Keywords:}

Blood donation

Ethiopia

Patient caregivers

Willingness

\begin{abstract}
A B S T R A C T
Background: Ethiopia is one of the countries with a significant shortage of medical blood. Patient caregivers can serve as an important pool of potential blood donors for many reasons. However, limited data are available on the willingness of patient caregivers to donate blood in Ethiopia. Therefore, this study assessed patient caregivers' willingness to donate blood and associated factors in northwest Ethiopia.

Methods: An institution-based cross-sectional study was conducted among 342 patient caregivers at the University of Gondar Comprehensive Specialized Hospital. A systematic random sampling technique was used to select the study participants. Data were collected using a pretested and interviewer-administered questionnaire. Data were entered into EPI data version 4.6 and exported to SPSS version 25 for analysis. The level of significance in the last model was declared based on a p-value of $<0.05$.

Results: Patients caregivers' willingness to donate blood was 78.1\% (95\% CI: 74, 82). Attending primary (AOR = 2.91; 95\% CI: $1.13,7.54$ ) and secondary education (AOR $=2.95 ; 95 \%$ CI: $1.19,7.28$ ), favorable attitude towards blood donation (AOR $=4.94$; 95\% CI: 2.62, 9.28), adequate knowledge of blood donation (AOR $=2.49 ; 95 \%$ CI: $1.18,5.22)$, and ever donated blood (AOR $=3.95 ; 95 \% \mathrm{CI}: 1.13,13.84$ ) were identified as significantly associated with willingness to donate blood.

Conclusion: In this study, more than three-quarters of patient caregivers were willing to donate blood. Community encouragement and continuous awareness and motivational speeches about the need for blood donations within the community and in medical facilities would have been important to motivate patient caregivers to donate blood.
\end{abstract}

\section{Introduction}

In the modern healthcare system, blood donation practice is essential and saves the lives of millions. ${ }^{1}$ It helps in managing patients presenting with severe symptomatic anemia or active life-threatening hemorrhage as a result of accidental injuries, surgical operations, malignancies, pregnancy, and childbirth-related complications, and other medical conditions necessitating transfusion. ${ }^{2}$ In this aspect, arranging and organizing blood donation centers on weekends and holidays is one of the most effective ways to increase blood donation practice and inspire people for future blood donation. ${ }^{3}$ In addition, strengthening community participation and ownership through involving religious and political leaders is found to increase the number of blood donors. ${ }^{4}$ This, in turn, will help motivate people to donate 1 unit of blood every 3 months. ${ }^{5}$ It should be noted, however, that blood donation is practiced regularly, voluntarily, and without any cost. ${ }^{6}$

The shortage of blood is a common problem in health institutions globally, particularly in low and middle-income countries. ${ }^{7}$ Approximately 80 million units of blood were collected from voluntary donors globally each year, though only 2 million units were collected in sub-Saharan Africa (SSA), where the need is very high. ${ }^{8}$ In SSA, a total of 18 million units of safe blood are required annually, but only $15 \%$ were collected. ${ }^{9}$ This is also a common problem in Ethiopia. In recent years, the Ethiopian blood bank collects nearly 200,000 units of blood from donors annually. However, the country requires around 18,000 units of

\footnotetext{
* Corresponding author.

E-mail address: azmuzwagholic@gmail.com (A.A. Kebede).
} 


\section{Abbreviations}

AOR Adjusted Odds Ratio

CI Confidence Interval

SSA sub-Saharan Africa

SPSS Statistical Package for Social Science

blood daily, yet the average amount of blood collected daily is approximately 1100 units with a shortfall of 16,900 units. ${ }^{10}$ To successfully overcome the observed gaps, there is a need for creating innovative and localized strategies by considering the culture of the community and the living environment. ${ }^{11}$

In SSA, the Maternal Mortality Ratio (MMR) is approximately $500-1000$ per 100,000 live births. ${ }^{12}$ About $30-50 \%$ of these deaths were attributable to postpartum hemorrhage ( $\mathrm{PPH}$ ) and more than two-thirds of mothers die without getting a blood transfusion. ${ }^{8}$ Besides, the global magnitude of injuries and death as a result of motor vehicle accidents is increasing, particularly in developing countries, including SSA. ${ }^{13}$ The majority of these deaths after traumatic injuries are as a result of hemorrhage which could be averted through transfusion of blood. ${ }^{14}$ However, there is a significant shortage of blood in developing countries disproportional to the needy population. This could be achieved by increasing the number of voluntary blood donors through multidimensional and integrative strategies.

Studies revealed that willingness to donate blood were $77.7 \%$ in Australia, ${ }^{15} 94.9 \%$ in Nigeria, ${ }^{16} 48 \%$ in Philippines, ${ }^{17} 53.1 \%$ in India, ${ }^{18}$ $70 \%$ in Botswana, ${ }^{19}$ and $37 \%$ in Ethiopia. ${ }^{20}$ Factors like attending higher education, ${ }^{19}$ having a family who had ever donated blood, ${ }^{19}$ ever experienced blood donation, having adequate knowledge of blood donation, ${ }^{21}$ and having a healthcare provider family ${ }^{5}$ had a significant association with willingness to donate blood.

So far, many efforts have been tried to increase voluntary blood donors including health education, public awareness creation in schools and streets, and campaign through social media. In addition, the Ethiopian blood bank has made many activities to minimize the community misconceptions regarding blood donation at the regional and national levels. ${ }^{22}$ However, unwillingness to donate blood is still the most common problem for the low proportion of blood donation practice in resource-limited countries, including Ethiopia. ${ }^{23}$ Thus, assessment of willingness to donate blood could have a great role in improving the availability of blood and blood products. In addition, there is limited data regarding willingness to donate blood among patient caregivers in Ethiopia, particularly in the study area. Therefore, this study assessed willingness to donate blood and associated factors among patient caregivers at the University of Gondar Comprehensive Specialized Hospital, northwest Ethiopia.

\section{Method and materials}

\subsection{Study design and setting}

An institution-based cross-sectional study was conducted at the University of Gondar Comprehensive Specialized Hospital from September 1-30, 2021. The University of Gondar Comprehensive Specialized Hospital is located in Amhara national regional state, Central Gondar zone, Gondar city. Gondar city is located $748 \mathrm{~km}$ northwest of Addis Ababa, the capital city of Ethiopia. The hospital provides medical education, training, and medical services. It serves patients who came from different areas, including Gondar city, central Gondar zone, West Gondar zone, and north and south Gondar zones, and other adjust zones and regions. According to the hospital's report, the average number of clients visiting the facility is 810 per day with an estimated 24,300 clients visiting the hospital per month. According to a recent report, there are around 615 patient beds and approximately 6818 admitted patients in the last three months (2272 patients per month).

\subsection{Population}

All patient caregivers at the University of Gondar Comprehensive Specialized Hospital were the source population. All patient caregivers at the University of Gondar Comprehensive Specialized Hospital (medical, surgical, pediatrics, and obstetrics/gynecology wards) during the study period were the study population. All eligible patient caregivers (i. e. who were potential candidates of blood donation such as people aged between 18 and 65 years old, weighing $50 \mathrm{~kg}$, and free of transmittable diseases) and willing to participate in the study were included.

\subsection{Sample size determination and sampling procedure}

The sample size (n) was determined by using the formula for a single population proportion taking willingness to donate blood ( $p=37 \%$ ) from previous research, ${ }^{20}$ level of confidence- $95 \%$, and margin of error-5\%. Therefore, $(n)=\frac{(Z \alpha / 2)^{2^{*}} \mathrm{p}(1-\mathrm{p})}{\mathrm{d}^{2}} \frac{=(1.96)^{2^{*}} 0.37^{*}(1-0.37)}{(0.05) 2}=359$. By considering a $5 \%$ non-response rate, the final minimum adequate sample size was 377 . The systematic sampling technique was used to get the study participants. All inpatient wards providing clinical services were considered and represented by a proportionally allocated number of study participants. There are around 615 inpatient beds and taking into account one patient-caregiver for one patient. The sampling interval $\left(\mathrm{K}^{\mathrm{th}}\right.$ value) was determined by dividing the total estimated patient-caregiver number in each ward by the calculated sample size. Thus, the sampling interval $\mathrm{K}^{\text {th }}(615 / 377)$ results to be 1.6 , approximated to 2 . The patient caregivers were taken every two intervals after taking the first study participant randomly. In the case of more than one patient caregiver, one patient-caregiver was taken by lottery method. Besides, some patients may be discharged and the bed may be occupied by a new patient. In this context, the data collectors were strongly advised to register the medical registration number of each patient and cross-check before the interview to minimize multiple interviews.

\subsection{Variables of the study}

Willingness (Yes/No) to donate blood was the dependent variable while age, sex, marital status, place of residence, occupation, level of education, average monthly income, residence, access to media, knowledge of blood donation, attitude towards blood donation, history of blood donation, known medical illness, and ever received blood were the independent variables.

\subsection{Operational definition}

Willingness to voluntary blood donation: participants were asked whether they are willing to donate blood in the future or not. Participants who answered "yes" were considered as willing to donate blood and coded as $1 . .^{17}$

Knowledge about blood donation: based on the summative scores designed to assess knowledge, those who scored above the mean value were categorized as knowledgeable, otherwise not knowledgeable. ${ }^{24}$

Attitude towards blood donation: based on the summative scores designed to assess participants' attitudes, those who were able to score above the mean score were considered as having favorable attitude, otherwise unfavorable attitude. ${ }^{24}$

\subsection{Data collection and analysis}

Data were collected by interview using a structured and intervieweradministered questionnaire. The questionnaire was prepared by reviewing previous studies. The questionnaire comprised of four parts; 
sociodemographic, participants' knowledge about blood donation, attitude towards blood donation, and blood transfusion-related questions. The questionnaire was developed in English then translated to the local language (Amharic) then back to English to ensure the steadiness of the questionnaire. Four graduate BSc in midwifery data collectors and one MSc in clinical midwifery supervisor have participated in the data collection process. A pre-test was done on $5 \%$ of the calculated sample size outside of the study area (Debark General hospital). Before the actual data collection, training was given for the data collectors and the supervisor on the data collection procedure. The completeness of the questionnaire was checked before data entry by the principal investigator. Incomplete data were discarded from the analysis and considered as none response. Data were entered into EPI DATA version 4.6 software and exported to SPSS version 25 for further analysis. Bivariable logistic regression analysis was performed and variables having a p-value of $<0.2$ were considered to be candidates to the multivariable logistic regression model. Crude and adjusted odds ratios with $95 \%$ confidence interval (CI) were computed to assess the association between the independent and outcome variables. A p-value of $<0.05$ was used to declare statistical association in the final model.

\subsection{Ethical considerations}

Ethical clearance was obtained from the School of Midwifery under the delegation of the University of Gondar Institutional Review Board (IRB). Permission was also assured from the University of Gondar Comprehensive Specialized Hospital. Anonymous written informed consent was obtained from each study participant. Respondents were also informed that they had the full right to withdraw or refuse the interview at any time.

\section{Result}

\subsection{Sociodemographic characteristics of the study participants}

A total of 342 study participants were included in the analysis, making a response rate of $90.72 \%$. The mean age of the study participants was 29.54 years old ( \pm 4.58 SD) and about two-fifths $(40.6 \%)$ of them were aged between 26 and 35 years. Slightly more than half $(51.5 \%)$ of the study subjects were females and nearly two-thirds $(65.5 \%)$ of them were urban dwellers. Regarding educational status, nearly half of the study participants attended secondary and above education and about $45.6 \%$ of them were government employees (Table 1).

\subsection{Blood transfusion-related characteristics}

Only a quarter (26\%) of the study participants ever donated blood and about $3.5 \%$ of them had transfused blood in their lifetime. More than fourth-fifths (85.4\%) of the study subjects were a member of the Ethiopian Red Cross society. About $43.6 \%$ of the study participants have ever seen a person transfused with blood (Table 2).

\subsection{Knowledge of the study participants about blood donation}

Of the total study participants, $59.9 \%$ had adequate knowledge of blood donation. About $60.2 \%$ of the study participants knew that blood donation is not harmful. In addition, nearly a quarter (22.2\%) of the study participants discerned that blood should be donated every three months. On the other hand, more than four-fifths (86.3\%) of the study subjects recognized that blood transfusion can transmit infection (Table 3).

\subsection{Attitude of the study participants about blood donation}

In this study, about two-thirds (66.7\%) of the study participants had
Table 1

Socio-demographic characteristics of the study participants at the University of Gondar Comprehensive Specialized Hospital, northwest Ethiopia, 2021 (n = 342).

\begin{tabular}{|c|c|c|}
\hline Characteristics & Frequency & Percentage \\
\hline \multicolumn{3}{|l|}{ Age in year } \\
\hline $18-25$ & 67 & 19.6 \\
\hline $26-35$ & 139 & 40.6 \\
\hline $36-45$ & 92 & 26.9 \\
\hline$>45$ & 44 & 12.9 \\
\hline \multicolumn{3}{|l|}{ Sex } \\
\hline Male & 166 & 48.5 \\
\hline Female & 176 & 51.5 \\
\hline \multicolumn{3}{|l|}{ Residence } \\
\hline Urban & 224 & 65.5 \\
\hline Rural & 118 & 34.5 \\
\hline \multicolumn{3}{|l|}{ Monthly income } \\
\hline$<500$ & 27 & 7.9 \\
\hline $501-1000$ & 27 & 7.9 \\
\hline $1001-1500$ & 19 & 5.6 \\
\hline$>1500$ & 269 & 78.7 \\
\hline \multicolumn{3}{|l|}{ Religion } \\
\hline Orthodox & 276 & 80.7 \\
\hline Muslim & 58 & 17 \\
\hline Protestant & 8 & 2.3 \\
\hline \multicolumn{3}{|l|}{ Educational status } \\
\hline Unable to read and write & 79 & 23.1 \\
\hline Able to read and write & 36 & 10.5 \\
\hline Primary (1-8) & 62 & 18.1 \\
\hline Secondary and above & 165 & 48.2 \\
\hline \multicolumn{3}{|l|}{ Occupational status } \\
\hline Farmer & 74 & 21.6 \\
\hline Merchant & 16 & 4.7 \\
\hline student & 96 & 28.1 \\
\hline government employee & 156 & 45.6 \\
\hline \multicolumn{3}{|l|}{ Marital status } \\
\hline Married & 10 & 2.9 \\
\hline \multirow{2}{*}{\multicolumn{3}{|c|}{ Known medical problem }} \\
\hline & & \\
\hline Yes & 28 & 8.2 \\
\hline No & 314 & 91.8 \\
\hline \multicolumn{3}{|c|}{ Health professional in a family } \\
\hline Yes & 125 & 36.5 \\
\hline No & 217 & 63.5 \\
\hline \multicolumn{3}{|c|}{ Previous voluntary participation in an other organizations } \\
\hline Yes & 91 & 26.6 \\
\hline No & 251 & 73.4 \\
\hline \multicolumn{3}{|l|}{ Access to media } \\
\hline Yes & 234 & 68.4 \\
\hline No & 108 & 31.6 \\
\hline
\end{tabular}

a favorable attitude towards blood donation. About $43.9 \%$ of the study participants strongly agree that blood should be donated voluntarily. A $45.3 \%$ of the study participants also strongly agree that blood should be donated continuously (Table 4).

\subsection{Willingness to donate blood and associated factors}

In the current study, patient caregivers' willingness to donate blood was found to be $78.1 \%$ (95\% CI: 74,82 ). The multivariable logistic regression analysis has been run to identify significant predictors of the outcome variable. Accordingly, attending primary education and above, having a favorable attitude towards blood donation, having adequate knowledge of blood donation, and ever donated blood were the factors significantly associated with the outcome variable in the last model.

The odds of having the willingness to donate blood was 2.91 and 2.95 times higher among study participants attending primary (AOR $=$ 2.91; $95 \%$ CI: $1.13,7.54$ ) and above secondary education (AOR $=2.95$; $95 \%$ CI: $1.19,7.28$ ) compared with their counterparts. Likewise, the odds of having a willingness to donate blood was nearly 5 times higher among patient caregivers who had a favorable attitude towards blood donation as compared to those who had an unfavorable attitude (AOR = 4.94; 95\% CI: $2.62,9.28$ ). Similarly, the odds of having willingness to 
Table 2

Blood transfusion related characteristics the study participants in the University of Gondar comprehensive specialized hospital, northwest Ethiopia, 2021 (n = 342).

\begin{tabular}{lcc}
\hline Characteristics & Frequency & Percentage \\
\hline Ever donate blood & 89 & \\
Yes & 253 & 26.0 \\
No & 35 & 74.0 \\
Frequency of donation (n= 89) & 38 & 39.3 \\
Once & 16 & 42.7 \\
Twice & 12 & 18.0 \\
Three and more times & 330 & \\
History of being transfused & 66 & 3.5 \\
Yes & 276 & 96.5 \\
No & 292 & 19.3 \\
History of blood transfusion to a family member & 80.7 \\
Yes & 50 & \\
No & 165.4 \\
Member for Ethiopian red cross society & 14.6 \\
Yes & 149 & \\
No & 193 & 43.6 \\
Ever seen a patient transfused with blood & 56.4 \\
Yes & 153 & 44.7 \\
No & 189 & 55.3 \\
Know a person died due to lack of blood & \\
Yes & & \\
No & & \\
\hline
\end{tabular}

Table 3

Knowledge of patient attendants about blood donation in the University of Gondar comprehensive specialized hospital, northwest Ethiopia, 2021 (n = 342).

\begin{tabular}{|c|c|c|}
\hline Characteristics & Frequency & Percentage \\
\hline \multicolumn{3}{|c|}{ Do you know blood donation is not harmful? } \\
\hline Yes & 206 & 60.2 \\
\hline No & 136 & 39.8 \\
\hline \multicolumn{3}{|c|}{ Do you know blood can be donated periodically? } \\
\hline Yes & 211 & 61.7 \\
\hline No & 131 & $38.3 \mathrm{~s}$ \\
\hline \multicolumn{3}{|c|}{ How frequently can a person donate blood? } \\
\hline Any time & 161 & 47.1 \\
\hline After a month & 105 & 30.7 \\
\hline After two to three months & 76 & 22.2 \\
\hline \multicolumn{3}{|c|}{ Do you know blood transfusion can transmit infection? } \\
\hline Yes & 295 & 86.3 \\
\hline No & 47 & 13.7 \\
\hline \multicolumn{3}{|c|}{$\begin{array}{l}\text { Do you know pregnant mothers who loss blood due to bleeding needs blood } \\
\text { transfusion? }\end{array}$} \\
\hline Yes & 293 & 85.7 \\
\hline No & 49 & 14.3 \\
\hline \multicolumn{3}{|c|}{ Do you know patients with severe accident $\&$ injuries needs blood transfusion? } \\
\hline Yes & 231 & 67.5 \\
\hline No & 111 & 32.5 \\
\hline \multicolumn{3}{|c|}{ Do you know anemic patients due to malaria needs blood transfusion? } \\
\hline Yes & 208 & 60.8 \\
\hline No & 134 & 39.2 \\
\hline \multicolumn{3}{|c|}{ Do you know places of blood donation? } \\
\hline Yes & 258 & 75.4 \\
\hline No & 84 & 24.6 \\
\hline \multicolumn{3}{|c|}{ Do you know as there is shortage of blood in health facilities? } \\
\hline Yes & 190 & 55.6 \\
\hline No & 152 & 44.4 \\
\hline \multicolumn{3}{|c|}{ Do you know blood donation should be voluntarily? } \\
\hline Yes & 282 & 82.5 \\
\hline No & 60 & 17.5 \\
\hline \multicolumn{3}{|c|}{ Do you know blood donation is important to donors? } \\
\hline Yes & 182 & 53.2 \\
\hline No & 160 & 46.8 \\
\hline
\end{tabular}

donate blood was 2.49 times higher among study participants who have had adequate knowledge of blood donation compared with study participants having inadequate knowledge (AOR $=2.49$; $95 \%$ CI: 1.18 , 5.22). This study also found that the likelihood of willingness to donate
Table 4

Attitude towards blood donation in the University of Gondar Comprehensive Specialized Hospital, northwest Ethiopia, 2021 ( $n=342)$.

\begin{tabular}{|c|c|c|c|c|c|}
\hline Characteristics & $\begin{array}{l}\text { Strongly } \\
\text { agree (\%) }\end{array}$ & $\begin{array}{l}\text { Agree } \\
(\%)\end{array}$ & $\begin{array}{l}\text { Neutral } \\
(\%)\end{array}$ & $\begin{array}{l}\text { Disagree } \\
(\%)\end{array}$ & $\begin{array}{l}\text { Strongly } \\
\text { disagree } \\
(\%)\end{array}$ \\
\hline $\begin{array}{l}\text { All people should } \\
\text { donate blood if } \\
\text { he/she is eligible }\end{array}$ & $\begin{array}{l}172 \\
(50.3)\end{array}$ & $9(2.6)$ & $\begin{array}{l}44 \\
(12.9)\end{array}$ & $4(1.2)$ & $133(33)$ \\
\hline $\begin{array}{l}\text { Blood should be } \\
\text { donated for } \\
\text { family members } \\
\text { only }\end{array}$ & $11(3.2)$ & $\begin{array}{l}49 \\
(14.3)\end{array}$ & $\begin{array}{l}40 \\
(11.7)\end{array}$ & $\begin{array}{l}169 \\
(49.4)\end{array}$ & 73 (21.3) \\
\hline $\begin{array}{l}\text { Blood donation is } \\
\text { harm full to } \\
\text { donors }\end{array}$ & $24(7.0)$ & $\begin{array}{l}43 \\
(12.6)\end{array}$ & $\begin{array}{l}60 \\
(17.5)\end{array}$ & $\begin{array}{l}188 \\
(55.0)\end{array}$ & 27 (7.9) \\
\hline $\begin{array}{l}\text { Blood donation } \\
\text { should be } \\
\text { voluntarily }\end{array}$ & $\begin{array}{l}150 \\
(43.9)\end{array}$ & $\begin{array}{l}16 \\
(4.7)\end{array}$ & $30(8.8)$ & $\begin{array}{l}132 \\
(38.6)\end{array}$ & $14(4.1)$ \\
\hline $\begin{array}{l}\text { financial } \\
\text { compensation } \\
\text { for blood } \\
\text { donation is } \\
\text { appropriate }\end{array}$ & $25(7.3)$ & $\begin{array}{l}42 \\
(12.3)\end{array}$ & $\begin{array}{l}39 \\
(11.4)\end{array}$ & $\begin{array}{l}150 \\
(43.9)\end{array}$ & $86(25.1)$ \\
\hline $\begin{array}{l}\text { Blood should be } \\
\text { donated } \\
\text { continuously }\end{array}$ & $\begin{array}{l}155 \\
(45.3)\end{array}$ & $\begin{array}{l}42 \\
(12.3)\end{array}$ & $\begin{array}{l}56 \\
(16.4)\end{array}$ & $8(2.3)$ & $81(23.7)$ \\
\hline $\begin{array}{l}\text { There is shortage } \\
\text { of blood in } \\
\text { health facilities }\end{array}$ & $\begin{array}{l}119 \\
(34.8)\end{array}$ & $\begin{array}{l}92 \\
(26.9)\end{array}$ & $\begin{array}{l}59 \\
(17.3)\end{array}$ & $4(1.2)$ & 68 (19.9) \\
\hline
\end{tabular}

blood was nearly 4 times higher among study participants who had ever donated blood as compared to those study participants who didn't ever donate blood (AOR = 3.95; 95\% CI: 1.13, 13.84) (Table 5).

\section{Discussion}

If blood is needed emergently and not available at hospitals, patient caregivers can be a major source of blood donation next to health professionals. However, their willingness to donate blood is crucial. Thus, this study assessed patient caregivers' willingness to donate blood and associated factors in northwest Ethiopia.

This study found that $78.1 \%$ of patient caregivers were willing to donate blood in the future. This result is in line with a study conducted in Australia, in which about $77.7 \%$ of the study participants were willing to donate blood in the future. ${ }^{15}$ However, the result of this study is lower compared with a study conducted in Kano Metropolis, Nigeria where $94.9 \%$ of the study participants were willing to donate blood. ${ }^{16}$ The variations might be explained by differences in the study population and sociodemographic characteristics. About a third (33.6\%) of the study participants in this study didn't attend formal education, whereas only $3.2 \%$ of the study participants in the Nigeria study didn't have formal education. It is expected that individuals having a higher level of education will have better knowledge and a positive attitude towards blood donation, thereby being willing to donate blood.

On the other hand, the finding of this study is higher than studies conducted in Philipines-48\%, ${ }^{17}$ India-53.1\%, ${ }^{18}$ European Union-60\%, ${ }^{25}$ Southeast Botswana-70\%, ${ }^{19}$ and other studies in Ethiopia including Dessie town-59.2\% ${ }^{26}$ and Mekelle city. ${ }^{20}$ The possible justification for the higher willingness in this study might be differences in the study population, time gap, and sociodemographic characteristics. Ensuring the health and well-being of the population is one of the global agendas, where national and international organizations give emphasis. The study in Saudi Arabia was conducted among students and only 5.8\% of them had previous experience of blood donation. However, about $26 \%$ of the study participants had the experience of blood donation in the current study. Studies confirmed that previous experience of blood donation increases willingness to donate blood constantly. ${ }^{5,17}$ Besides, $59.9 \%$ of the study participants in the current study had adequate 
Table 5

Factors associated with willingness to donate blood among patient attendants at the University of Gondar Comprehensive Specialized Hospital, northwest Ethiopia, $2021(\mathrm{n}=342)$.

\begin{tabular}{|c|c|c|c|c|}
\hline \multirow[t]{2}{*}{ Variables } & \multirow{2}{*}{$\begin{array}{l}\text { Willingness } \\
\text { Yes }\end{array}$} & \multirow{2}{*}{$\begin{array}{l}\text { COR } \\
(95 \% \mathrm{CI}) \\
\text { No }\end{array}$} & \multirow[t]{2}{*}{ AOR $(95 \% \mathrm{CI})$} & \\
\hline & & & & \\
\hline \multicolumn{5}{|l|}{ Residence } \\
\hline Urban & 193 & 31 & $\begin{array}{l}3.75 \\
(2.09,6.08)\end{array}$ & $1.11(0.39,3.19)$ \\
\hline Rural & 75 & 43 & 1 & 1 \\
\hline \multicolumn{5}{|c|}{ Educational status } \\
\hline $\begin{array}{l}\text { Unable to read } \\
\text { and write }\end{array}$ & 45 & 34 & 1 & 1 \\
\hline $\begin{array}{l}\text { Able to read and } \\
\text { write }\end{array}$ & 24 & 12 & $\begin{array}{l}1.51 \\
(0.66,3.44)\end{array}$ & $1.97(0.74,5.21)$ \\
\hline $\begin{array}{l}\text { Primary } \\
\text { education }\end{array}$ & 53 & 9 & $\begin{array}{l}4.45 \\
(1.93,10.26)\end{array}$ & $\begin{array}{l}2.91 \\
(1.13,7.54) *\end{array}$ \\
\hline $\begin{array}{l}\text { Secondary and } \\
\text { above }\end{array}$ & 146 & 19 & $\begin{array}{l}5.81 \\
(3.02,11.16)\end{array}$ & $\begin{array}{l}2.95 \\
(1.19,7.28)^{*}\end{array}$ \\
\hline \multicolumn{5}{|c|}{ Occupational status } \\
\hline Farmer & 61 & 13 & 1 & 1 \\
\hline Merchant & 12 & 4 & $\begin{array}{l}0.64 \\
(0.18,2.30)\end{array}$ & $0.71(0.16,3.09)$ \\
\hline student & 60 & 36 & $\begin{array}{l}0.35 \\
(0.17,0.74)\end{array}$ & $0.88(0.32,2.42)$ \\
\hline $\begin{array}{c}\text { government } \\
\text { employee }\end{array}$ & 135 & 21 & $\begin{array}{l}1.37 \\
(0.64,2.92)\end{array}$ & $0.54(0.18,1.59)$ \\
\hline \multicolumn{5}{|c|}{ Health professional in a family } \\
\hline Yes & 103 & 22 & $\begin{array}{l}1.48 \\
(0.85,2.57)\end{array}$ & $1.04(0.52,2.06)$ \\
\hline No & 165 & 52 & 1 & 1 \\
\hline \multicolumn{5}{|c|}{ Voluntary participation in other organizations } \\
\hline Yes & 82 & 9 & $\begin{array}{l}3.18 \\
(1.51,6.70)\end{array}$ & $1.99(0.87,4.56)$ \\
\hline \multicolumn{4}{|l|}{ Attitude } & 1 \\
\hline $\begin{array}{l}\text { Unfavorable } \\
\text { attitude }\end{array}$ & 73 & 41 & 1 & 1 \\
\hline favorable attitude & 195 & 33 & $\begin{array}{l}3.32 \\
(1.95,5.65)\end{array}$ & $\begin{array}{l}4.94 \\
(2.62,9.29) * *\end{array}$ \\
\hline \multicolumn{5}{|l|}{ Knowledge } \\
\hline Inadequate & 86 & 51 & 1 & 1 \\
\hline Adequate & 182 & 23 & $\begin{array}{l}4.69 \\
(2.69,8.18)\end{array}$ & $\begin{array}{l}2.49 \\
(1.18,5.22)^{*}\end{array}$ \\
\hline \multicolumn{5}{|l|}{ Access to media } \\
\hline Yes & 196 & 38 & $\begin{array}{l}2.58 \\
(1.52,4.38)\end{array}$ & $0.64(0.28,1.44)$ \\
\hline No & 72 & 36 & 1 & 1 \\
\hline \multicolumn{5}{|l|}{ Ever donate blood } \\
\hline Yes & 51 & 3 & $\begin{array}{l}5.67 \\
(1.72,18.7)\end{array}$ & $\begin{array}{l}3.95 \\
(1.13,13.84) *\end{array}$ \\
\hline No & 216 & 72 & 1 & 1 \\
\hline \multicolumn{5}{|c|}{ Ever seen a women being transfused } \\
\hline Yes & 127 & 22 & $\begin{array}{l}2.13 \\
(1.22,3.70)\end{array}$ & $0.77(0.37,1.62)$ \\
\hline No & 141 & 52 & 1 & 1 \\
\hline \multicolumn{5}{|c|}{ Blood transfusion history for a family } \\
\hline Yes & 58 & 2 & $\begin{array}{l}2.28 \\
(1.04,5.02)\end{array}$ & $1.74(0.74,4.07)$ \\
\hline No & 210 & 66 & 1 & 1 \\
\hline
\end{tabular}

Notes: * p-value $\leq 0.05, * *$ p value $\leq 0.01$; Abbreviations: AOR, adjusted odds ratio; COR, crude odds ratio; CI, confidence interval; 1 , reference category.

knowledge of blood donation, while only $37.7 \%$ of the study subjects in India had adequate knowledge of blood donation. It has been evidenced that adequate knowledge of blood donation is a key for blood donation practice and future willingness. ${ }^{27}$

This study declared that level of education was significantly associated with willingness to donate blood in the future. Thus, study participants who accomplished primary and secondary education were 2.91 and 2.95 times more likely to have had the willingness to donate blood in the future compared with those participants who were unable to read and write. This finding is supported by a study conducted in Southeast
Botswana. ${ }^{19}$ This could be explained by the fact that individuals attending higher education are expected to have good knowledge or awareness of blood donation and a positive attitude towards blood donation. Evidence indicated that higher-level education increases the knowledge and positive attitude of individuals, thereby encouraging people to donate blood continually. ${ }^{23}$

Attitude towards blood donation was found to be significantly associated with willingness to donate blood. Accordingly, the odds of willingness to donate blood in the future among study participants who had a favorable attitude was nearly 5 times higher as compared to those participants who had an unfavorable attitude. A similar finding was reported from a study conducted in Saudi Arabia, wherein individuals having a positive attitude was more likely to have had a future intention for bio-specimen donation. ${ }^{28}$ To do or think about something, one must first have a positive attitude towards the planned or perceived behavior. Besides, a positive attitude is crucial for any health-seeking practice. ${ }^{29}$

In this study, the previous history of blood donation has been significantly associated with willingness to donate blood in the future. The odds of willingness to donate blood among individuals who had blood donation experience was nearly 4 times higher than those who didn't have blood donation practice. This finding is in accordance with a study conducted in Saudi Arabia. ${ }^{5}$ This could be possibly justified by individuals who had the experience of blood donation will get adequate information about the need for donating blood on a regular basis. Another important explanation might be individuals with a previous history of a blood donation may want to donate blood as soon as they understand that the blood they donate saves many lives and does not cause any harm to them.

This study also depicts that the knowledge of participants had a significant association with willingness to donate blood. Hence, the odds of willingness to donate blood for the future was 2.49 times higher among study participants who had adequate knowledge of blood donation compared with those who had inadequate knowledge of blood donation. It is well known that knowledge is the engine to perform any health behavior and a road map for health-related decisions. Lastly, we are pleased to acknowledge some of the limitations that might be encountered in this study. First, it may not be possible to infer a causeeffect relationship between the outcome and explanatory variables. In addition, social desirability bias might have been introduced since the information was self-reported. However, a better way of understanding was given for the study participants to give factual information. Despite these limitations, this study will provide important input for the existing gap regarding blood donation.

\section{Conclusion}

In this study, more than three-quarters of the study participants were willing to donate blood in the future. Attending primary and more education, ever donated blood, adequate knowledge of blood donation, and favorable attitude towards blood donation were significantly associated with willingness to donate blood. Programmed and continuous awareness about blood donation to the community is expected to have intensified effects on the general population. This, in turn, will build adequate knowledge and a positive attitude towards blood donation and conserve consistent blood supply to the needy. Additional efforts will also be made in collaboration with other sectors, thereby inspiring the population to donate blood on a regular basis.

\section{Data sharing statement}

The datasets used and/or analyzed during the current study are available from the corresponding author on reasonable request.

\section{Consent to publish}

Not applicable. 


\section{Funding}

The research was not supported by any grant.

\section{Authors' contributions}

AAK was involved in the conception and design of the study, participated in data collection, analyzed the data, drafted the manuscript, and approved the final version of the manuscript. YB, KYW, TB, ZM, WA, NST, and TAA approved the proposal with some revisions, participated in data analysis, and revised subsequent drafts of the manuscript, and approved the last version of the manuscript. All authors have read and approved the manuscript.

\section{Declaration of competing interest}

The authors declare that they have no competing interests.

\section{Acknowledgments}

We are very grateful to the University of Gondar for approval of the ethical clearance. Our gratitude also goes to the School of Midwifery, health facilities, data collectors, and study participants.

\section{References}

1 Nwabueze S, Nnebue C, Azuike E, et al. Perception of blood donation among medical and pharmaceutical science students of Nnamdi Azikiwe University. Awka. Open J Prev Med. 2014;4:515-522.

2 World Health Organization \& International Federation of Red Cross and Red Crescent Societies. Towards 100\% Voluntary Blood Donation: A Global Framework for Action. World Health Organization; 2010. https://apps.who.int/iris/handle/10665/44359.

3 New strategies for maintaining blood supplies from donations may be cost-effective. Natl Inst Heal Res. Published online. 2019. https://doi.org/10.3310/signal-000731.

4 Wolrd helath organization blood safety progress in Ethiopia. Published online www. afro.who.int/en/ethiopia/who-country-office-ethiopia.html; 2014.

5 Alshamlan NA, Shammari MAA, Alomar RS, et al. ABO and Rhesus blood group distribution and blood donation willingness among first-year health students in a Saudi university. J Blood Med. 2021;12:551-560. https://doi.org/10.2147/JBM. S316845.

6 Blood Safety and Availability. World Health Organization; 2020. Published online htt ps://www.who.int/news-room/fact-sheets/detail/blood-safety-and-availability.

7 Getie A, Wondmieneh A, Bimerew M. Knowledge of Blood Donation and Associated Factors in Ethiopia : A Analysis Systematic Review and Meta. 2021:1-7. https://doi.org/ 10.1136/bmjopen-2020-044343. Published online.

8 Hadush A, Dagnaw F, Getachew T, Bailey PE, Lawley R, Ruano AL. Triangulating data sources for further learning from and about the MDSR in Ethiopia: a crosssectional review of facility based maternal death data from EmONC assessment and MDSR system. BMC Pregnancy Childbirth. 2020;20(206).

9 Nigatu A, Demissie D. Knowledge, attitude and practice on voluntary blood donation and associated factors among Ambo University Regular Students, Ambo Town, Ethiopia. J Community Med Health Educ. 2014;4(5).
10 United Nations Office on Drugs and crime. Ethiopia Rolls up Sleeves for Blood Donation. Ethiopian National Blood Bank; 2020. Published online.

11 Allain J. Current approaches to increase blood donations in resource-limited countries. Transfus Med. 2019;29:297-310. https://doi.org/10.1111/tme.12629.

12 Lancaster Lian, Barnes Richard FW, Correia Momade, et al. Maternal death and postpartum hemorrhage in sub-Saharan Africa - a pilot study in metropolitan Mozambique. Res Pr Thromb Haemost. 2020;4:402-412.

13 Adeloye D, Thompson JY, Akanbi MA, et al. The burden of road traffic crashes, injuries and deaths in Africa: a systematic review and meta-analysis. Bull World Health Organ. 2016;94(7):510.

14 yeniyi BT, Fox EE, Scerbo M, Tomasek JS, Wade CE, Holcomb JB. Trends in 1029 trauma deaths at a level 1 trauma center: impact of a bleeding control bundle of care. Injury. 2017;48(1):5-12.

15 Clackett S, Seed CR, Prestage G, et al. Attitudes and willingness to donate blood among gay and bisexual men in Australia. Transfusion. 2020;60(5):965-973. https:// doi.org/10.1111/trf.15768.

16 Abduljaleel A, Amole T, Olatunji LK. A community survey of the willingness, perceptions and practice of blood donation among adults in Kano Metropolis. Int J Public Heal Epidemiol Res. 2019;5(2):100-107.

17 Leon MSD, Ejv B, Regla En D, et al. Willingness to blood donation among the residents of Bustos, Bulacan, Philippines: a prevalence study. Int $J$ Chem Res. 2018;11 (8):70-79. https://doi.org/10.20902/ijctr.2018.110808.

18 Desai K, Satapara V. A study on knowledge, attitude, and practice on blood donation among health professional students in Anand: Gujarat. J Appl Hematol. 2014;5(2):51. https://doi.org/10.4103/1658-5127.137140.

19 Pule PI, Rachaba B, Magafu MGMD, Habte D. Factors associated with intention to donate blood: sociodemographic and past experience variables. J Blood Transfus. 2014;2014:1-7. https://doi.org/10.1155/2014/571678.

20 Mirutse G. Intention to donate blood among the eligible population in Mekelle city, northern Ethiopia: using the theory of planned behavior. Am J Health Res. 2014;2(4): 158. https://doi.org/10.11648/j.ajhr.20140204.19.

21 Ameen H, Isiaka-Lawal S, Okesina B, et al. Willingness to support antenatal blood donation among married men in a Metropolitan City in North-central Nigeria. Niger Postgrad Med J. 2015;22(3):169. https://doi.org/10.4103/1117-1936.170742.

22 Blood saftey strengthening program from may 13- sebtember 2019.Ethiopia national blood bank service. https://www.jembi.org/Project/Blood-Safety-Strength ening-Programme-(BSSP).

23 Getie A, Wondmieneh A, Bimerew M, Gedefaw G, Demis A. Knowledge of blood donation and associated factors in Ethiopia: a systematic review and meta-analysis. BMJ Open. 2021;11(7):1-7. https://doi.org/10.1136/bmjopen-2020-044343.

24 Jemberu YA, Esmael A, Ahmed KY. Knowledge, attitude and practice towards blood donation and associated factors among adults in Debre Markos town, Northwest Ethiopia. BMC hematology. 2016;16(1):1-8.

25 de Kort WLAM, Merz EM. Determinants of blood donation willingness in the European Union: a cross-country perspective on perceived transfusion safety, concerns, and incentives. Transfusion. 2019;59(4):1273-1282. https://doi.org/ $10.1111 / \operatorname{trf} .15209$.

26 Dejene M, Tefera A, Dires A, Gedamu S, Getachew Y, Ademe S. Low blood donation practice of health sciences college students in northeast Ethiopia: a cross-sectional study. J Blood Med. 2021;12:43-51. https://doi.org/10.2147/JBM.S287398.

27 Jemberu YA, Esmael A, Ahmed KY. Knowledge, attitude and practice towards blood donation and associated factors among adults in Debre Markos town, Northwest Ethiopia. BMC Hematol. 2016;16(1):1-8. https://doi.org/10.1186/s12878-0160062-8.

28 Merdad L, Aldakhil L, Gadi R, et al. Assessment of knowledge about biobanking among healthcare students and their willingness to donate biospecimens. BMC Med Ethics. 2017;18(1):1-11. https://doi.org/10.1186/s12910-017-0195-8.

29 Oberoi S, Chaudhary N, Patnaik S, Singh A. Understanding health seeking behavior. J Fam Med Prim Care. 2016;5(2):463. https://doi.org/10.4103/2249-4863.192376. 